\title{
Genetische Impfstoffe gegen COVID-19: Hoffnung oder Risiko?
}

\section{Clemens Arvay}

Dipl.-Ing., Biologe, freier Autor, Graz

Es wird häufig davon ausgegangen, dass sich das globale Sozialleben erst normalisieren wird, wenn ein Impfstoff gegen SARS-CoV2 zur Verfügung steht. Fast die Hälfte der Impfstoffkandidaten sind genetische Impfstoffe, welche einige gesundheitliche Risiken bergen.

\section{Die Biologie von SARS-CoV-2}

SARS-CoV-2 gehört zur Familie der Coronaviren (Coronaviridae). Das virale Genom liegt bei diesen nicht als DNA (Desoxyribonukleinsäure), sondern als RNA (Ribonukleinsäure) vor. Die Virionen des Erregers mit einem Durchmesser von etwa $120 \mathrm{~nm}$ bestehen aus einer Lipiddoppelschichthülle mit Membran- und Stachelproteinen, in deren Inneren die genomische RNA (vRNA für «viral RNA») im Querschnitt ringförmig im Nukleokapsid angeordnet ist [1].

Nach dem Eintritt in die Wirtszelle kommt es dort zur Expression der Boten-RNA (mRNA für «messenger RNA»), die aus einsträngigen Transkripten von Abschnitten der viralen RNA besteht. Über Eingriffe in

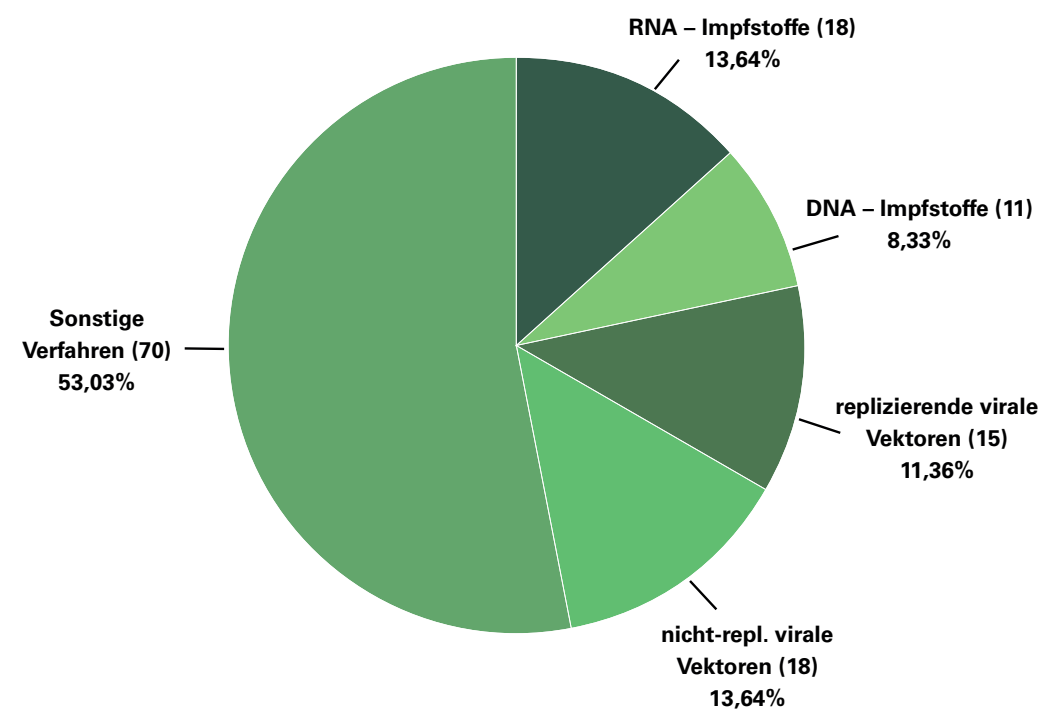

Bei der WHO gemeldete nukleinsäurebasierte (d.h. genetische) Impfstoffkandidaten (rechts) im Verhältnis zu sonstigen (Stand: 2.6.2020). peripher-genetische Abläufe in der Wirtszelle findet die Translation der Boten-RNA an den Ribosomen statt, in denen die Proteinbiosynthese abläuft. In der Folge kommt es zur Synthese viraler Proteine [2].

\section{Genbasierte Impfstoffe}

Viele Experten gehen davon aus, dass sich unser Alltag erst normalisieren wird, wenn ein wirksamer Impfstoff gegen SARS-CoV-2 zur Verfügung steht [3]. Unter den Kandidaten befindet sich ein signifikanter Anteil genbasierter, das heisst auf der Transduktion von Nukleinsäuren in die menschliche Zielzelle aufbauender Impfstoffe [4]. Bei der Weltgesundheitsorganisation (WHO) wurden von pharmazeutischen Unternehmen 18 RNA- und 11 DNA-basierte Impfstoffstudien für eine Immunisierung gegen COVID-19 angemeldet (von 132) [5]. Hinzu kommen 33 virale Vektorimpfstoffe, bei denen durch Manipulation eines Trägervirus ebenfalls eine Übertragung von DNA oder RNA stattfindet. Genetische Ansätze werden öffentlich als erfolgversprechende Kandidaten gehandhabt [6] und unter anderen von Bill Gates und Christian Drosten favorisiert [7-9].

\section{DNA-basierte Immunisierung}

Ein DNA-basierter Impfstoffkandidat gegen COVID-19 wurde in den Vereinigten Staaten von Amerika für einen klinischen Test in Phase 1 zugelassen [10]. Die DNA-Technologie nutzt Plasmiden: ringförmige, doppelsträngige DNA-Moleküle. Diese stammen im Regelfall ursprünglich von Bakterien oder werden synthetisch hergestellt. Den Plasmiden wird die genetische Information zur Synthese von mindestens einem Pro- 
tein eingesetzt, welches einem spezifischen Protein des Erregers für eine geeignete Immunantwort ausreichend ähnelt [11]. Dabei kann es sich zum Beispiel um ein virales Stachelprotein handeln.

Standardmässig nach Absorption der modifizierten DNA an Goldpartikeln erfolgt die Verabreichung mittels hohen Drucks durch eine «Genkanone», wobei die Partikel in Muskel- und Bindegewebszellen steckenbleiben, wo sie so wie die zelleigenen Gene enzymatisch von Transkriptasen abgelesen und zu Boten-RNA transkribiert werden. Nach Translation der Boten-RNA an den Ribosomen wird das virale Protein produziert und fungiert sodann als Antigen [12].

Als adverser Effekt ist die Bildung von Antikörpern gegen DNA möglich, was unerwünschte Autoimmunreaktionen auslösen könnte [13]. Bei Toleranzentwicklung gegen das Antigen könnte es zu Spätfolgen mit verminderter Immunantwort gegen verwandte Erreger kommen [14]. Die Immunogenität der DNA-Impfstoffe ist vergleichsweise gering, so dass nach derzeitigem Stand Wiederholungen der Immunisierung nötig und die Langzeitwirkungen nicht ausreichend gesichert wären [15]. Neben diesen grundsätzlichen Fragen besteht vor allem das Risiko einer unbeabsichtigten und zufälligen Insertion von DNA ins Genom der Zielzelle, was eine Aktivierung von Onkogenen oder eine Deaktivierung antikarzinogener DNA-Sequenzen bewirken und das Tumorrisiko erhöhen könnte [16].

Dieselben Problemfelder treffen auch auf DNA-basierte Immunisierungen mittels viraler Vektoren zu. Die genetischen Informationen für das erregerspezifische Antigen werden dabei in das Genom von DNA-Viren wie beispielsweise Adenoviren eingesetzt, welche in der Zielzelle durch Transkription die entsprechende Boten-RNA freisetzen. Die viralen Integrationsmechanismen können zur Aufnahme von DNA in den Zellkern führen und sind somit ebenfalls mit dem potenziellen Risiko der Tumorbildung behaftet [17].

\section{RNA-Impfstoffe als Favoriten?}

Die erste bislang in Deutschland zugelassene klinische Studie für eine Immunisierung gegen SARS-CoV-2 betrifft einen RNA-Impfstoff und befindet sich in der klinischen Phase 1 [18]. Auch in den USA sowie in Grossbritannien sind die ersten Kandidaten, die für die klinische Phase 1 zugelassen wurden, RNA-Impfstoffe [19, 20]. Die RNA-Plattform bringt synthetisch hergestellte mRNA zur Synthese eines erregerspezifischen Antigens mittels Lipidnanopartikeln in die Zielzelle ein, so dass die Translation sowie die darauffolgende Proteinbiosynthese des viralen Antigens in den Ribosomen erfolgen und entsprechende Antikörper gegen Bestandteile von SARS-CoV-2 gebildet werden [21].

Offene Fragen betreffen vor allem das synthetische Design des Antigens. Die Boten-RNA muss einerseits so gestaltet werden, dass sie humane mRNA mimt, um von der Zielzelle verarbeitet zu werden. Anderseits muss das Antigen jenem von SARS-CoV-2 ausreichend ähneln, um eine Immunität zu gewährleisten. Neben solchen grundlegenden Problemstellungen liegen konkrete Hinweise für mögliche gesundheitliche Langzeitfolgen durch RNA-Immunisierungen vor. So haben präklinische Studien mit RNA-Impfstoffen gegen SARS und MERS das Risiko schwerwiegender entzündlicher Veränderungen des Lungengewebes offengelegt, die über eine Überreaktion der Th2-Lymphozyten vermittelt werden [22]. Diese Bedenken gelten grundsätzlich auch, wenn die mRNA über einen viralen Vektor eingebracht wird (in der Regel RNA-Viren wie Retro-, Lentioder Alphaviren).

\section{Plädoyer für das Vorsorgeprinzip}

Von den bei der WHO gemeldeten Kandidaten wurden bisher 10 für die klinischen Phasen 1 oder 2 zugelassen, davon $50 \%$ genetische (2 RNA-, 1 DNA- und 2 virale Vektorimpfstoffe). Üblicherweise muss ein Kandidat vor der Zulassung drei klinische Phasen erfolgreich durchlaufen. Erst die Phase 3 dient der Feststellung von Langzeitwirkung sowie zeitverzögerten Nebenwirkungen und dauert typischerweise 4-6 Jahre. Nachdem in dieser Phase ausreichend lange Follow-up-Zeiträume nötig sind, führt jede Verkürzung zu einem höheren Risiko, dass eine Langzeitnebenwirkung übersehen wird. Im öffentlichen Diskurs werden unter Verweis auf die Haftung des Staates häufig die Aussetzung von Impfregularien und die Verkürzung der klinischen Phasen in Erwägung gezogen [23, 24]. Medizinethische Fragen sollten dabei nicht umgangen werden. Verkürzungen in den klinischen Phasen bergen insbesondere das Risiko, dass zeitverzögerte Nebenwirkungen erst erkannt werden, nachdem der Impfstoff bereits breitenwirksam angewendet wurde. Betroffenen ist mit einer blossen monetären Abfindung durch die öffentliche Hand für mögliche erlittene Gesundheitsschäden nicht geholfen. Daher sollten die politischen Entscheidungsträger nachdrücklich auf das Vorsorgeprinzip hingewiesen werden. Eine Immunisierung gegenüber COVID-19 könnte generell problematisch sein. Frühere Versuche, Impfstoffe gegen Coronaviren zu entwickeln, scheiterten [25]. Vakzinen gegen das feline Coronavirus FIPV führten zu adversen Effekten, so dass bei immunisierten Katzen die Wahrscheinlichkeit, die Erkrankung zu entwickeln, anstieg [26]. Bei einem bislang favorisier- 
ten RNA-Kandidaten gegen SARS-CoV-2 zeigte sich jüngst im Primatenversuch, dass das Vakzin zu keiner ausreichenden Immunität führt, obwohl dieser Kandidat bereits zuvor eine Zulassung zur klinischen Phase 1 erhalten hatte [27]. Es muss auch bedacht werden, dass sich Coronaviren möglicherweise relativ rasch verändern. Wir sollten am Ende nicht mit einem im Eilver-

\section{Das Wichtigste in Kürze}

- Unter den Impfstoffkandidaten gegen SARS-CoV-2 befindet sich ein signifikanter Anteil genetischer Impfstoffe (62 von 132 = 47\%), das heisst: Impfstoffe, die auf der Transduktion von Nukleinsäuren (DNA oder RNA) in die menschlichen Zielzellen basieren.

- Genetische Impfstoffe können jedoch Gesundheitsrisiken wie beispielsweise inflammatorische Autoimmunreaktionen und (im Fall der DNA-Plattform) Aktivierung von Onkogenen bergen.

- Der Autor argumentiert, dass Vereinfachungen und Verkürzungen von Zulassungsverfahren einen Verstoss gegen das Vorsorgeprinzip darstellen würden.

\section{Literatur}

1 Tobler K, Ackermann M und Fraefel C. Allgemeine Virologie, S. 330. Bern: UTB / Haupt Verlag; 2016.

2 Tobler K, Ackermann M und Fraefel C. Allgemeine Virologie, S. 97-107. Bern: UTB / Haupt Verlag; 2016.

3 Britneff B. No return to 'normality' until coronavirus vaccine is available, Trudeau says. Global News, 9.4.2020 $\rightarrow$ globalnews.ca. Letzter Aufruf: 29.4.2020.

4 Le TT, Andreatakis Z, Kumar A, Román R, Tollefsen, Saville M und Mayhew S. The COVID-19 vaccine development landscape. Nature Reviews: Drug Discovery. 2020.

Letzter Aufruf: 29.4.2020.

5 World Health Organization, DRAFT landscape of COVID-19 candidate vaccines -2 . Juni $2020 \rightarrow$ who.int. Letzter Aufruf: 8.6.2020.

6 Schmidt C. Genetic engineering could make a COVID-19 vaccine in months rather then years: candidates are speeding toward human trials. Scientific American, 29.4.2020 $\rightarrow$ scientificamerican.com. Letzter Aufruf: 30.4.2020.

7 Kelley A. Bill Gates sees RNA vaccines as best options for quick coronavirus treatment. The Hill, 1.5.2020 $\rightarrow$ thehill.com. Letzter Aufruf: 29.4.2020.

8 Gates B. The first modern pandemic: the scientific advances we need to stop COVID-19. Gates Notes, 23.4.2020 $\rightarrow$ gatesnotes.com. Letzter Aufruf: 30.4.2020.

9 Brey M. NDR-Podcast: Corona-Impfstoff: Virologe Drosten nennt zwei Möglichkeiten - «hoffnungsvolle Anfangsdaten». Merkur.de, 4.4.2020 $\rightarrow$ merkur.de. Letzter Aufruf: 29.4.2020.

10 Pagliarulo N. Inovio begins first human test of experimental coronavirus vaccine. Biopharma Dive, 7.4.2020 $\rightarrow$ biopharmadive. com. Letzter Aufruf: 29.4.2020.

11 Murphy K, Travers P und Walport M. Janeway Immunologie, 7. Auflage, S. 880. Berlin / Heidelberg: Springer / Spektrum; 2014.

12 Tobler K, Ackermann M und Fraefel C. Allgemeine Virologie, S. 263-5. Bern: UTB / Haupt Verlag; 2016.

13 Medjitna T, Stadler C, Bruckner L, Griot C und Ottinger H. DNA vaccines: safety aspect assessment and regulation. Developments of Biologicals. 2006;126:261-70 $\rightarrow$ ncbi.nlm.nih.gov. Letzter Aufruf: 29.4.2020.

14 Schalk J, Mooi F, Berbers G, van Aerts L, Ovelgönne H und Kimman T. Preclinical and clinical safety studies on DNA vaccines. Human Vaccines. 2006;2(2):45-53 $\rightarrow$ iconicwoman.com. Letzter Aufruf: 29.4.2020. fahren zugelassenen Impfstoff der Evolution des Coronavirus hinterherhinken. Politische Entscheidungen müssen gerade jetzt unter sorgfältiger Abwägung möglicher Risiken getroffen werden. Das Vorsorgeprinzip wäre dafür ein idealer Leitfaden.

\section{Bildnachweis}

Darstellung von Clemens Arvay nach Daten von WHO Blueprint.

\section{L'essentiel en bref}

- Parmi les vaccins candidats contre le SRAS-CoV-2, il existe une part importante de vaccins génétiques ( 62 sur $132=47 \%$ ), soit des vaccins basés sur la transduction d'acides nucléiques (ADN ou ARN) dans les cellules cibles humaines.

- Les vaccins génétiques peuvent cependant présenter des risques pour la santé, tels que des réactions auto-immunes inflammatoires et (dans le cas de la plateforme ADN) I'activation d'oncogènes.

- L'auteur fait valoir que les simplifications et les raccourcissements des procédures d'autorisation enfreindraient le principe de précaution.

15 Hobernik D und Bros M. DNA vaccines: how far from clinical use? International Journal of Molecular Sciences. 2018;9(11):3605 $\rightarrow$ ncbi. nlm.nih.gov. Letzter Aufruf: 29.4.2020.

16 Hasson S, Al-Busaidi J und Sallam T. The past, current, and future trends in DNA vaccine immunisations. Asian Pacific Journal of Tropical Biomedicine. 2015;5(5):344-53 $\rightarrow$ sciencedirect.com: Letzter Aufruf: 29.4.2020

17 Ura T, Okuda K und Shimada M. Development in viral vector based vaccines. Vaccines. 2014;2(3):624-41 $\rightarrow$ ncbi.nlm.nih.gov. Letzter Aufruf: 29.4.2020.

18 Karberg S und Vogt R. Erste klinische Studie in Deutschland zugelassen. Der Tagesspiegel, 22.4.2020 $\rightarrow$ tagesspiegel.de. Letzter Aufruf: 29.4.2020.

19 Etherington D. First US clinical human trial of potential coronavirus vaccine set to start Monday. TechCrunch, 16.3.2020 $\rightarrow$ techcrunch.com. Letzter Aufruf: 29.4.2020.

20 McKee S. UK COVID-19 vaccine to begin human testing. Pharma Times, 22.4.2020 $\rightarrow$ pharmatimes.com. Letzter Aufruf: 29.4.2020.

21 Verbece R, Lentacker I, De Schmedt S und Dewitte H. Three decades of messenger RNA vaccine development. NanoToday. 2019;28(100766) $\rightarrow$ sciencedirect.com. Letzter Aufruf: 30.4.2020.

22 Lurie N, Saville M, Hatchett R und Halton J. Perspective: Developing COVID-19 vaccines at pandemic speed. The New England Journal of Medicine. $2020 \rightarrow$ nejm.org. Letzter Aufruf: 29.4.2020.

23 Bill Gates, englisches Originalzitat: «There will be a trade-off, we will have less safety testing than we typically would have». BBC Breakfast, 12.4.2020, ab 7 Min. 40 Sek. $\rightarrow$ youtube.com. Letzter Aufruf: 29.4.2020

24 Gillmann B. SARS-Impfstoffe: Virologe Drosten: «Wir müssen Regularien für Impfstoffe ausser Kraft setzen». Handelsblatt, 19.3.2020 $\rightarrow$ handelsblatt.com. Letzter Aufruf: 29.4.2020.

25 Jiang S. Don't rush to deploy COVID-19 vaccines and drugs without sufficient safety guarantees. Nature, 16.3.2020 $\rightarrow$ nature.com. Letzter Aufruf: 29.4.2020

26 Takano T, Yamada S, Doki T und Hohdatsu T. Pathogenesis of oral type one feline infectious peritonitis virus (FIPV) infection: antibody-dependent enhancement infection of cats with type I FIPV via the oral route. Journal of Veterinary Medical Science. 2019; 81(6):799-48 $\rightarrow$ jstage.jst.go.jp. Letzter Aufruf: 29.4.2020.

27 Newey S und Nuki P. Doubts over Oxford vaccine as it fails to stop coronavirus in animal trials. The Telegraph, 18.5.2020 $\rightarrow$ telegraph. co.uk. Letzter Aufruf: 8.6.2020. 